\title{
Hyperinsulinaemia as a predictor of coronary heart disease mortality in a healthy population: the Paris Prospective Study, 15-year follow-up
}

\author{
A.Fontbonne ${ }^{1}$, M. A. Charles ${ }^{1}$, N. Thibult ${ }^{1}$, J. L. Richard ${ }^{2}$, J. R. Claude ${ }^{3}$, J.M. Warnet ${ }^{3}$, G. E. Rosselin ${ }^{4}$ and E. Eschwège $^{1}$ \\ ${ }^{1}$ INSERM U21, Villejuif, ${ }^{2}$ INSERM U258, ${ }^{3}$ Center for Prevention of Cardiovascular Diseases, DASES, and \\ ${ }^{4}$ INSERM U55, Paris, France
}

\begin{abstract}
Summary. The Paris Prospective Study is a long-term, largescale study of the factors predicting coronary heart disease. The first follow-up examination included, for subjects not known as having diabetes mellitus, a $75 \mathrm{~g}$ oral glucose tolerance test with measurement of plasma insulin and glucose levels, fasting and $2 \mathrm{~h}$ post-load. Between 1968 and 1973 , 6903 men aged $43-54$ years were thus examined. Causes of death were ascertained within this group after 15 years of mean follow-up. The baseline variables were tested as predictors of death from coronary heart disease by a Cox regression analysis. Significant independent predictors of coronary heart disease death were: systolic blood pressure, number of cigarettes per day, plasma cholesterol level, and $2 \mathrm{~h}$ post-load plasma insulin level when entered as a categorical variable (below or above $452 \mathrm{pmol} / \mathrm{l}$, i.e. the lower limit of the fifth quintile of the distribution). This dichotomization was performed to account for the non-linear univariate distribution of deaths with increasing post-load insulin values. Fasting
\end{abstract}

plasma insulin level was not an independent predictor of death by coronary heart disease over this long-term followup. Levels of blood glucose were not significant independent predictors of death by coronary heart disease when plasma insulin levels were included in the model. The same applied to abnormalities of glucose tolerance when the 125 men with known non-insulin-treated diabetes at baseline were added to the group. Under the assumption that hyperinsulinaemia is a marker of insulin resistance, the results are consistent with the hypothesis that insulin resistance is associated with a higher risk of coronary heart disease mortality. However, it is doubtful that circulating insulin per se is a direct cause of arterial complications.

Key words: Epidemiology, Paris Prospective Study, coronary heart disease risk factors, plasma insulin level, insulin resistance.
Clinical complications of atherosclerosis remain a major cause of mortality in most developed countries. Epidemiologic data supported by three large prospective surveys initiated independently in the late sixties, have suggested a role for hyperinsulinaemia as an independent risk factor for coronary heart disease (CHD) [1-3].

However, though some fundamental studies appear to give support to the hypothesis of a link between plasma insulin levels and atherosclerotic lesions [4], the epidemiologic evidence has recently been questioned [5]. The question under debate mainly relates to the potential causality of the relationship between hyperinsulinaemia per se and clinical manifestations of atherosclerosis. Though causality is not a problem to be solved by non-interventional epidemiologic studies, the weakening or the disappearance of the predictive power of a variable over an event in such studiescan be considered as an argument against causality [6] .

Therefore, it was deemed relevant to study whether the predictive power of hyperinsulinaemia over CHD death, assessed in the Paris Prospective Study at 11-year followup [1], remained unchanged over a longer follow-up period.

Recently, the follow-up for deaths in the Paris Prospective Study was extended to 15 years. The aim of the present work was to analyse the factors which independently contributed to the prediction of CHD death over this follow-up period, with a particular focus on plasma insulin levels.

\section{Subjects and methods}

The Paris Prospective Study is a long-term prospective investigation of the risk factors for cardiovascular disease in a middle-aged male population, namely male employees of the Paris Civil Service aged 42-53 years at entry. The general aims, detailed methodology (in compliance with the Declaration of Helsinki, 1964) and population characteristics of the study have been previously described [7] and only data relevant to the present analysis will be summarized here. 
Table 1. Comparison of baseline variables (mean $\pm \mathrm{SD}$ ) between subjects who died from coronary heart disease (CHD) during the 15year follow-up (group A, $n=174$ ), and subjects who died from another cause or who were alive at the end of follow-up (group B, $n=6540$ )

\begin{tabular}{|c|c|c|}
\hline Group & A & B \\
\hline Age (years) & $49.0 \pm 2.0$ & $48.5 \pm 2.0$ \\
\hline $\mathrm{SBP}(\mathrm{mm} \mathrm{Hg})$ & $156.0 \pm 29.1$ & $143.7 \pm 21.4$ \\
\hline $\mathrm{DBP}(\mathrm{mm} \mathrm{Hg})$ & $87.9 \pm 16.0$ & $81.3 \pm 12.8$ \\
\hline CHOL $(\mathrm{mmol} / \mathrm{l})$ & $5.98 \pm 1.06$ & $5.63 \pm 1.07$ \\
\hline $\mathrm{TG}(\mathrm{mmol} / \mathrm{l})^{\mathrm{a}}$ & $1.36 \pm 0.02$ & $1.24 \pm 0.02$ \\
\hline $\mathrm{ClG}$ (no/day) & $12.9 \pm 10.4$ & $9.1 \pm 10.3$ \\
\hline $\operatorname{BMI}\left(\mathrm{kg} / \mathrm{m}^{2}\right)$ & $26.7 \pm 3.2$ & $26.0 \pm 3.3$ \\
\hline $\mathrm{FPI}(\mathrm{pmol} / 1)^{\mathrm{a}}$ & $80.6 \pm 14.1$ & $71.0 \pm 13.8$ \\
\hline $2 \mathrm{hPI}(\mathrm{pmol} / 1)^{\mathrm{a}}$ & $263.1 \pm 16.8$ & $233.9 \pm 16.1$ \\
\hline$\%$ with FPI > $108 \mathrm{pmol} / /^{\mathrm{b}}$ & $32.2 \%$ & $22.6 \%$ \\
\hline$\%$ with $2 \mathrm{hPI}>452 \mathrm{pmol} / \mathrm{I}^{\mathrm{b}}$ & $31.0 \%$ & $19.6 \%$ \\
\hline $\mathrm{FBG}(\mathrm{mmol} / \mathrm{l})$ & $5.9 \pm 1.0$ & $5.7 \pm 0.8$ \\
\hline $2 \mathrm{hBG}(\mathrm{mmol} / \mathrm{l})$ & $6.3 \pm 2.8$ & $5.9 \pm 2.2$ \\
\hline $\begin{array}{l}\% \text { with } 2 \mathrm{hBG}>7.8 \mathrm{mmol} / \mathrm{l}^{\mathrm{c}} \\
\text { (or with known diabetes) }\end{array}$ & $21.0 \%$ & $13.5 \%$ \\
\hline
\end{tabular}

All differences between $A$ and $B$ are statistically significant at at least $p<0.05$, except for $2 \mathrm{~h}$ insulin taken continuously $(p<0.06)$. Only subjects with complete information for all variables are included $(n=6714)$.

Abbreviations: SBP - systolic blood pressure; DBP - diastolic blood pressure; CHOL - plasma cholesterol; $\mathrm{TG}$ - plasma triglyceride; CIG - cigarette smoking; BMI - body mass index; FPI - fasting plasma insulin; $2 \mathrm{hPI}-2 \mathrm{~h}$ post-load plasma insulin; $\mathrm{FBG}$ - fasting blood glucose $; 2 \mathrm{hBG}-2 \mathrm{~h}$ post-load blood glucose.

a Geometric mean and SD (log-transformation);

$b$ i.e. belonging to the last quintile of the distribution;

c i. e. with impaired glucose tolerance or diabetes according to WHO criteria, 1985 [12]

The first annual follow-up session (1968-1973) was attended by 7434 male employees of the Paris Civil Service, aged 43-54 years who gave consent to participate in the study. It included a cardiovascular clinical examination, biological measurements, and a medical history questionnaire. At the time of this examination, $270 \mathrm{men}$ with diagnosed cardiovascular disease were excluded from the follow-up. Blood pressure was measured by standard cuff technique, with the subjects in the sitting position. Body mass index was calculated as the ratio of weight $(\mathrm{kg})$ by squared height $\left(\mathrm{m}^{2}\right)$. Cigarette consumption was recorded, and an overnight fasting venous blood sample was taken for measurement of serum cholesterol, triglyceride, plasma glucose and insulin levels. A 75 g oral glucose tolerance test was performed on 6903 subjects with no evidence of cardiovascular disease or diabetes, and plasma glucose and insulin were measured $2 \mathrm{~h}$ after the glucose load. Insulin measurements were performed by standard radioimmunoassay [8].

The group considered for analysis in the present paper consists of these 6903 men plus 125 known non-insulin-treated diabetic subjects. The ten insulin-treated diabetic subjects of the population were excluded from the analyses, since the presence of exogenous insulin interfered with the interpretation of plasma insulin values.

All deaths up to 1 January 1987 (mean follow-up: 15 years) were counted and certified using the following procedure. Deaths were systematically reported by the different administrative departments of the Paris Civil Service, with a $98 \%$ completeness as estimated by cross-checking the register of all subjects included in the study. Additional enquiries to families, general practitioners, or hospitals, were organized to obtain information regarding the circumstances and causes of death. The underlying cause of death was then ascertained and coded by a panel of physicians. Coding was performed according to the International Classification of Diseases (8th revision, to continue with the classification in use at the time of the previous reckoning points of the study). In the present analysis, only deaths caused by CHD to a large extent were considered, i. e. (1) myocardial infarction: codes 410.0 to 414.9 , representing $29 \%$ of all CHD deaths; (2) sudden death: code 795.0 , representing $51 \%$ of all $\mathrm{CHD}$ deaths; (3) heart failure: codes 782.0 to 782.9 and codes $427.0,427.1$, 519.1 , representing $20 \%$ of all CHD deaths. In view of the French death certification characteristics, this grouping has been shown to adequately represent ischaemic cardiac deaths, and the distribution is consistent with French mortality data [9].

\section{Statistical analysis}

For statistical analyses, subjects with missing values for one or more variables used in the test were excluded. The basic comparisons were made between subjects who died from CHD and subjects who were alive or who died from another cause, to remain consistent with previous reports from the Paris Prospective Study (the differences were all more marked when subjects who died from a non-CHD cause were excluded from the comparisons). All testing methods were usual parametric ones. Multivariate analyses of the predictive power of baseline variables towards CHD death used the Cox regression model [10]. In the case of a non-linear relationship between a variable and CHD mortality, the variable was either log-transformed or categorized in order to ensure a better fit to statistical modelling. Because of the narrow age-range of the population, no adjustment for age was made for univariate analyses. However, age was forced into the equation of the Cox model. All statistical analyses were made using the SAS statistical package [11].

\section{Results}

At 15-year follow-up, subjects who died from CHD $(n=174)$ differed significantly on all baseline variables listed in Table 1 from those who were alive or who died from another cause. The highest $p$-values for differences $(p<0.0001)$ were those for blood pressure, plasma cholesterol level, and smoking habits. Subjects who died from CHD had higher plasma insulin levels, both fasting (FPI) $(p<0.01)$ and $2 \mathrm{~h}$ post-load $(2 \mathrm{hPI})(p<0.06)$, and were significantly more likely to have their plasma insulin levels

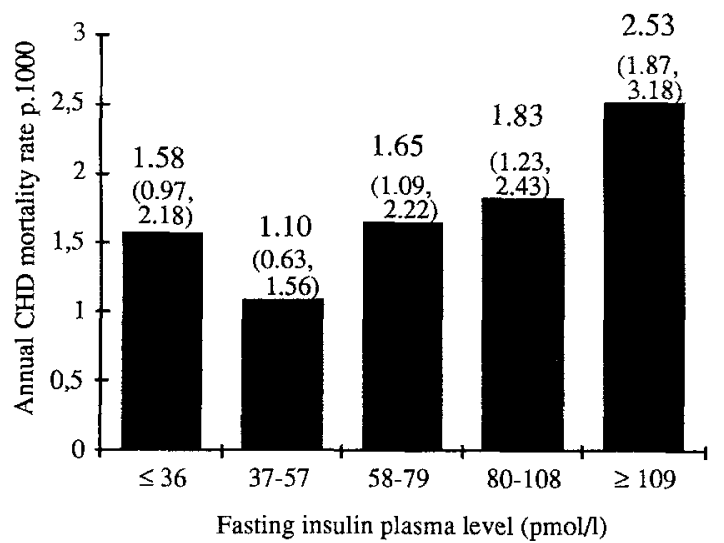

Fig. 1. Annual mortality rates for coronary heart disease (CHD) along quintiles of fasting plasma insulin levels at entry to 15 -year follow-up. Number of subjects with complete information: 6937. Number of CHD deaths: 178 . On top of bars: annual mortality rates and $95 \%$ confidence intervals in parentheses 


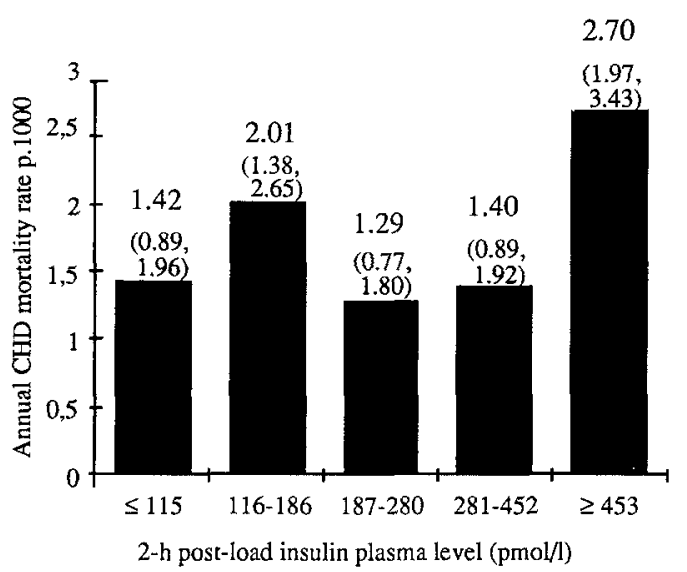

Fig. 2. Annual mortality rates for coronary heart disease (CHD) along quintiles of $2 \mathrm{~h}$ post-load plasma insulin levels at entry to 15 year follow-up. Number of subjects with complete information: 6889. Number of CHD deaths: 178 . On top of bars: annual mortality rates and $95 \%$ confidence intervals in parentheses

in the upper quintile of the distribution (FPI, $p<0.01$; $2 \mathrm{hPI}, p<0.001)$. The distribution of annual CHD mortality rates along quintiles of fasting insulin (Fig. 1) and of $2 \mathrm{~h}$ post-load insulin (Fig. 2) indicated that the risk increased more regularly along quintiles of FPI than along quintiles of $2 \mathrm{hPI}$. CHD mortality risk was clearly highest in the last quintile of $2 \mathrm{hPI}$ distribution, but appeared also fairly high in the second quintile. To question whether this observation could be accounted for by sampling vari- ations, CHD-related baseline variables were compared across quintiles of $2 \mathrm{hPI}$. The results did not show any particular cluster of CHD risk factors in the second quintile of 2 hPI (Table 2); on the contrary, all values seemed to increase regularly across quintiles. The possibility of a differing distribution of CHD-related causes of death was also checked: though numbers were small within each quintile of $2 \mathrm{hPI}$, no obvious trend was detected (from first to last quintile, percentage of sudden deaths: $64 \%, 50 \%$, $52 \%, 50 \%, 47 \%$; percentage of myocardial infarctions: $7 \%, 33 \%, 28 \%, 33 \%, 33 \%$ ). Thus, no explanation other than sampling variations could readily account for the CHD mortality rate in the second quintile of $2 \mathrm{hPI}$ compared to the others.

All variables related to CHD risk were generally related to each other (Table 3), which showed the necessity of multivariate adjustment to identify the independent predictors of CHD death. The Cox proportional hazards regression model [10] was used for this purpose, and two models were proposed and tested, in relation to the different distributions of CHD mortality with insulin plasma levels, regularly increasing with increasing FPI, vs more abruptly increasing in the last quintile of $2 \mathrm{hPI}$. The results of the regression analysis are shown in Table 4.

Model 1 proposed all variables as continuous, therefore fitting a model where CHD mortality risk increased continuously with increasing levels of the variables tested. To allow for the basal distribution of the variables in the population, plasma insulin levels (fasting and $2 \mathrm{~h}$ post-

Table 2. Values of baseline variables (mean \pm SD) according to quintiles of $2 \mathrm{~h}$ post-load plasma insulin level at entry to follow-up

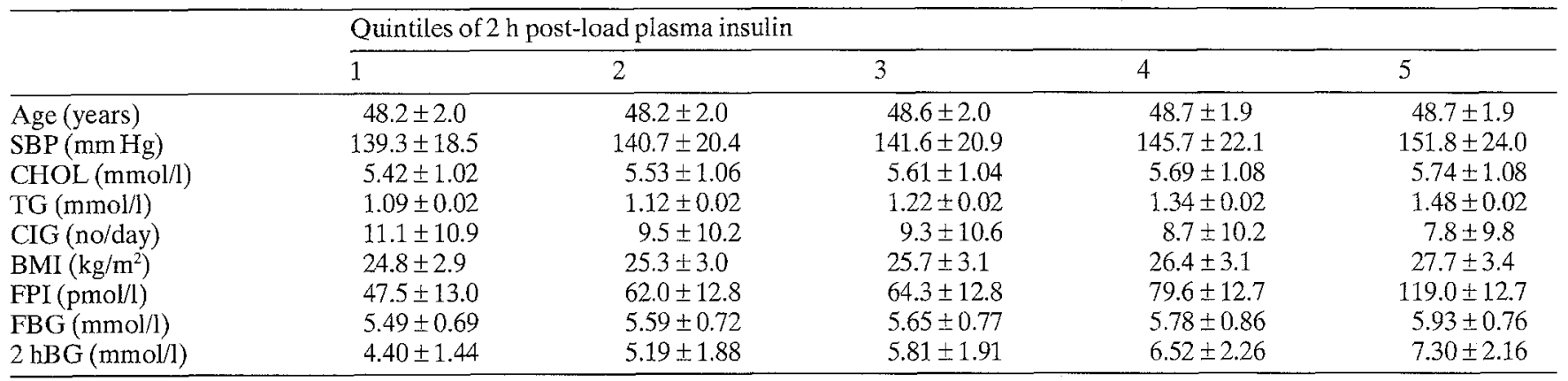

Abbreviations: SBP - systolic blood pressure; CHOL - plasma cholesterol; TG - plasma triglyceride; CIG - cigarette smoking; BMI - body mass index; FPI - fasting plasma insulin; FBG - fasting blood glucose; $2 \mathrm{hBG}-2 \mathrm{~h}$ post-load blood glucose

Table 3. Correlation matrix between variables tested in multivariate analysis

\begin{tabular}{|c|c|c|c|c|c|c|c|c|c|c|}
\hline & Age & SBP & $\mathrm{CHOL}$ & TG & $\mathrm{CIG}$ & BMI & FPI & $2 \mathrm{hPI}$ & $\mathrm{FBG}$ & $2 \mathrm{hBG}$ \\
\hline Age & 1 & & & & & & & & & \\
\hline SBP & 0.127 & 1 & & & & & & & & \\
\hline CHOL & $0.007^{\mathrm{a}}$ & 0.138 & 1 & & & & & & & \\
\hline $\mathrm{CIG}$ & $-0.003^{a}$ & $-0.019^{\mathrm{a}}$ & $0.008^{a}$ & 0.057 & 1 & & & & & \\
\hline BMI & 0.044 & 0.344 & 0.159 & 0.273 & -0.094 & 1 & & & & \\
\hline FPI & $0.003^{a}$ & 0.220 & 0.073 & 0.247 & -0.091 & 0.430 & 1 & & & \\
\hline $2 \mathrm{hBG}$ & 0.048 & 0.275 & 0.093 & 0.175 & -0.035 & 0.167 & 0.205 & 0.467 & 0.588 & 1 \\
\hline
\end{tabular}

Abbreviations: SBP-systolic blood pressure; $\mathrm{CHOL}$ - plasma cholesterol; TG - plasma triglyceride; CIG - cigarette smoking; BMI body mass index; FPI - fasting plasma insulin; $2 \mathrm{hPI}-2 \mathrm{~h}$ post-load plasma insulin; FBG - fasting blood glucose; $2 \mathrm{hBG}-2 \mathrm{~h}$ post-load blood glucose

a Not statistically significant $(p>0.05)$ 
Table 4. Cox multivariate analysis of predicting variables for coronary heart disease (CHD) mortality at 15-year follow-up

\begin{tabular}{|c|c|c|c|c|c|}
\hline \multicolumn{3}{|l|}{ Model 1} & \multicolumn{3}{|l|}{ Model 2} \\
\hline & $\begin{array}{l}\text { Regression coefficient } t^{\mathrm{a}} \\
\text { (standard error) }\end{array}$ & $p$ value $^{\mathrm{b}}$ & & $\begin{array}{l}\text { Regression coefficient }{ }^{\mathrm{a}} \\
\text { (standard error) }\end{array}$ & $p$ value $^{\mathrm{b}}$ \\
\hline SBP & $0.185(0.027)$ & 0.0001 & SBP & $0.171(0.027)$ & 0.0001 \\
\hline $\mathrm{CIG}$ & $0.033(0.006)$ & 0.0001 & $\mathrm{CIG}$ & $0.034(0.006)$ & 0.0001 \\
\hline $\mathrm{CHOL}$ & $0.005(0.002)$ & 0.003 & CHOL & $0.005(0.002)$ & 0.004 \\
\hline $\mathrm{FBG}$ & (not entered) & 0.52 & FBG & (not entered) & 0.64 \\
\hline $2 \mathrm{hBG}$ & (not entered) & 0.63 & $2 \mathrm{hBG}$ & (not entered) & 0.91 \\
\hline BMI & (not entered) & 0.77 & BMI & (not entered) & 0.74 \\
\hline $\log T G$ & (not entered) & 0.69 & $\log T G$ & (not entered) & 0.47 \\
\hline
\end{tabular}

Age was forced into the equation. Only subjects with complete information on all variables are included $(n=6714)$. Abbreviations: SBP - systolic blood pressure; CHOL - plasma cholesterol; TG - plasma triglyceride; CIG - cigarette smoking; BMI - body mass index; FPI fasting plasma insulin; $2 \mathrm{hPI}-2 \mathrm{~h}$ post-load plasma insulin; CLFPI classes of FPI (below or above $108 \mathrm{pmol} / \mathrm{l}$ ); CL2 hPI - classes of

load) and plasma triglyceride level were log-transformed. Significant independent predictors were: blood pressure, smoking, and plasma cholesterol level. Fasting plasma insulin level, though not significantly and independently related to CHD mortality, was the next factor to be entered in the model at a $p$-value of 0.13 .

Model 2 proposed plasma insulin levels as dichotomous variables (last quintile of the distribution: yes/no). Plasma triglyceride level was log-transformed to be tested. Other variables were tested as continuous natural values. In this model, $2 \mathrm{~h}$ post-load plasma insulin appeared as a significant independent predictor of CHD death, after blood pressure, smoking, and plasma cholesterol level.

Plasma glucose levels, fasting or $2 \mathrm{~h}$ post-load, never appeared as significantly and independently related to CHD mortality. To ensure that it was not because they were taken as continuous variables, another model was tested where $2 \mathrm{~h}$ post-load plasma glucose was dichotomized, below or above the threshold proposed by the World Health Organisation for impaired glucose tolerance $(7.8 \mathrm{mmol} / \mathrm{l})$ [12]. This also allowed inclusion of all known non-insulin-treated diabetic subjects of the population, in the class above the threshold. With this model, independent predictors of CHD death remained exactly the same, with the same order of entry and significance level, with plasma insulin levels either taken continuously or dichotomized. Dichotomized $2 \mathrm{~h}$ post-load glucose level never reached a sufficiently significant $p$-value to be entered in the model ( $p$-values to propose for entry were 0.27 in the model with continuous insulin values and 0.65 in the model with dichotomized insulin values).

\section{Discussion}

The present analysis of the Paris Prospective Study confirms previous results on the major risk factors of coronary heart disease mortality, i.e. blood pressure, smoking, and plasma cholesterol levels.
The original finding within the Paris Prospective Study at 15-year follow-up is the predictive power of $2 \mathrm{~h}$ postload plasma insulin level (last quintile vs first four quintiles), independently of all other variables. However, when plasma insulin levels were entered into the regression equation as continuous variables, neither fasting nor $2 \mathrm{~h}$ post-load insulinaemia appeared as independent predictors, whereas with this same model fasting insulinaemia was an independent predictor at 11-year followup [1]. This influence of modelling on the results of the multiple regression analysis derived from the different shapes of the distribution of CHD mortality along quintiles of fasting plasma insulin level on the one hand (Fig. 1), and of $2 \mathrm{~h}$ post-load plasma insulin level on the other hand (Fig. 2). It is worth noting that in the Helsinki Policemen Study [2], the equivalent distributions showed an inverse pattern compared to the Paris Prospective Study: CHD incidence rates increased linearly with postload insulinaemia, and abruptly with the last quintile of fasting insulinaemia. This may explain why with the same modelling (insulin levels being taken as continuous variables), one study (Helsinki) [2] found post-load insulin levels to be independent predictors whereas the other (Paris) [1] found fasting insulin levels to be such. This inconsistency in results was one major argument for questioning the validity of regarding insulinaemia as being related to $\mathrm{CHD}$ [5]. However, in all three prospective studies that measured plasma insulin levels at entry to follow-up [1-3], insulinaemia, fasting or stimulated depending on the model, was consistently the only significant factor related to CHD risk in men when major measured predictors (age, blood pressure, smoking, total plasma cholesterol level) were taken into account. It is worth noting that blood glucose values or diabetes and abnormalities of glucose tolerance were ruled out of the prediction model when plasma insulin levels were entered into the equation. The same was true for the plasma triglyceride levels and body mass index. As all these variables are closely linked (Table 3 ), one interpretation of this finding is that insulinaemia is the most important "sum- 
mary" variable for predicting CHD risk, at least in predominantly non-diabetic subjects (since diabetic subjects were a very small proportion of the group analysed, and it is already known that their CHD risk is better predicted by triglyceride plasma level [13]). Therefore, it can be considered that the 15-year follow-up analysis of the Paris Prospective Study gives renewed strength to the hypothesis that high insulin plasma levels are related, although probably in an indirect way, to an increased incidence of complications of atherosclerosis [4].

The problem of the causality of the relationship is not one that epidemiologic observational studies can directly solve. However, the evidence given here does not support such a causality between plasma insulin levels per se and CHD risk, as the relationship, though consistent, is much weaker (both in $p$-values and in consistency across studies, or over different lengths of follow-up) than the relationship between CHD and blood pressure, cholesterol or cigarette consumption. It is also true, as was pointed out by Jarrett [5], that lipoprotein fractions have not been measured as baseline variables, and therefore could well be the "actual" predictors of CHD, especially with regard to the negative relationship between insulin and HDLcholesterol plasma levels $[14,15]$. Besides, what exactly is measured by the insulin radioimmunoassay may actually be a mixture of several insulin-like peptides [16], obscuring further the issue of causality at the biological level, though a contrario denoting that the epidemiological relationship between insulin and CHD risk must be strong to be detected despite the apparently poor reliability of the measure $[4,17]$.

Let apart the causality, what can definitely be derived from prospective observations is that high immunoreactive insulin plasma levels certainly indicate and mark the existence of a cardiovascular risk factor, or risk situation.

Since insulin was first hypothesized to be a cardiovascular risk factor, or marker [18, 19], and since epidemiologic cross-sectional or prospective studies gave support to this hypothesis $[3,20,21]$, a number of studies have focussed on the clustering of metabolic disturbances, including hyperinsulinaemia, that are associated with insulin resistance [22-25]. There seems to be increasing evidence that potentially atherogenic abnormalities are consistently found in subjects with high plasma insulin levels, including non-insulin-dependent diabetic subjects [26-28]: a particular lipoprotein profile (high triglyceride, low HDL-cholesterol), elevated blood pressure, glucose intolerance. This association of risk factors has recently received the name of syndrome $X[29,30]$, and Reaven has given an overview of how this "syndrome" could explain the risk of developing both cardiovascular disease and non-insulin-dependent diabetes [29]. Epidemiologic studies so far appear to support this explanation. Independent predictors of cardiovascular complications, after the classic major ones, are hyperinsulinaemia, or low plasma HDL-cholesterol levels [31, 32], or high triglyceride plasma levels $[13,33,34]$, depending on the characteristics of the population and on what was measured at entry to follow-up. Also, hyperinsulinaemia has been found to be a predictor of future diabetes in subjects with normal glucose tolerance [35-38], and a common trait in offspring of non-insulin-dependent diabetic parents [3941].

In view of this evidence, it may well be that the high cardiovascular risk of non-insulin-dependent diabetic patients develops before the appearance of substantial hyperglycaemia [29, 42]. The confirmation in the Paris Prospective Study that hyperinsulinaemia remains a marker of CHD-related death risk indicates that the research on insulin resistance, or syndrome $\mathrm{X}$, may eventually offer new alternatives in the prevention of cardiovascular diseases, particularly in subjects "at risk" for non-insulin-dependent diabetes mellitus.

Acknowledgements. The Paris Prospective Study is coordinated by the Study Group for the Epidemiology of Atherosclerosis (GREA), supported by the French National Institute of Health and Medical Research (INSERM, U.21, U.55, U.169, U.258) and the Direction of Social Affairs, Childhood and Health (DASES), Paris, France.

\section{References}

1. Eschwège $\mathrm{E}$, Richard JL, Thibult $\mathrm{N}$, Ducimetière $\mathrm{P}$, Warnet JM, Claude JR, Rosselin GE (1985) Coronary heart disease mortality in relation with diabetes, blood glucose and plasma insulin levels. The Paris Prospective Study, ten years later. Horm Metab Res 15 [Suppl]: $41-46$

2. Pyörälä K, Savolainen E, Kaukola S, Haapakoski J (1985) Plasma insulin as coronary heart disease risk factor: relationship to other risk factors and predictive value during $91 / 2$-year follow-up of the Helsinki Policemen Study population. Acta Med Scand 701 [Suppl]: 38-52

3. Welborn TA, Wearne K (1979) Coronary heart disease and cardiovascular mortality in Busselton with reference to glucose and insulin concentrations. Diabetes Care 2: 154-160

4. Stout RW (1990) Insulin and atheroma. 20-yr perspective. Diabetes Care 13: 631-654

5. Jarrett RJ (1988) Is insulin atherogenic? Diabetologia 31: 71-75

6. Hill AB (1965) The environment and disease: association or causation? Proc Roy Soc Med 58: 295-300

7. Ducimetière P, Richard JL, Claude JR (1981) Les cardiopathies ischémiques: incidence et facteurs de risque. L'Etude Prospective Parisienne. Editions INSERM, Paris

8. Rosselin G, Assan R, Yalow RS, Berson SA (1966) Separation of antibody bound and unbound peptide hormone labelled with iodine 131 by talcum powder and precipitates silica. Nature 212: 355-357

9. Richard JL (1973) Quelques informations sur la fréquence en France des maladies cardiovasculaires, particulièrement des cardiopathies ischémiques. In: Ducimetière P (ed) Epidémiologie et prévention des maladies cardiovasculaires. Colloques de l'INSERM, Vol 21. Editions INSERM, Paris, pp 11-46

10. Cox DR (1972) Regression models and life tables (with discussion). J Roy Statist Soc B34: 187-220

11. SAS Institute Inc (1985) SAS User's Guide: Statistics. Version 5 Edition. SAS Institute Inc, Cary NC

12. WHO Expert Committee (1985) Diabetes Mellitus. Technical Report Series 727, WHO, Geneva

13. Fontbonne A, Eschwège E, Cambien F, Richard JL, Ducimetière P, Thibult N, Warnet JM, Claude JR, Rosselin GE (1989) Hypertriglyceridaemia as a risk factor of coronary heart disease mortality in subjects with impaired glucose tolerance or diabetes: results from the 11-year follow-up of the Paris Prospective Study. Diabetologia 32: 300-304

14. Stalder M, Pometta D, Suenram A (1981) Relationship between plasma insulin levels and high density lipoprotein cholesterol levels in healthy men. Diabetologia 21:544-548 
15. Laakso M, Pyörälä K, Voutilainen E, Marniemi J (1987) Plasma insulin and serum lipids and lipoproteins in middle-aged non-insulin-dependent diabetic and non-diabetic subjects. Am J Epidemiol 125: 611-621

16. Temple RC, Carrington CA, Luzio SD, Owens DR, Schneider AE, Sobey WJ, Hales CN (1989) Insulin deficiency in non-insulin-dependent diabetes. Lancet I: 293-295

17. Nagi DK, Hendra TJ, Ryle AJ, Cooper TM, Temple RC, Clark PMS, Schneider AE, Hales CN, Yudkin JS (1990) Relationships of concentrations of insulin, intact pro-insulin and 32-33 split pro-insulin with cardiovascular risk factors in Type 2 (non-insulin-dependent) diabetic subjects. Diabetologia 33: 532-537

18. Nikkilä EA, Miettinen TA, Vesenne MR, Pelkonen R (1965) Plasma insulin in coronary heart disease. Lancet II: 508-511

19. Stout RW, Vallance-Owen J (1979) Insulin and atheroma. Lancet I: $1078-1080$

20. Pyörälä K (1979) Relationship of glucose tolerance and plasma insulin to the incidence of coronary heart disease: results from two population studies in Finland. Diabetes Care 2: 131-141

21. Ducimetière P, Eschwège E, Papoz L, Richard JL, Claude JR, Rosselin GE (1980) Relationship of plasma insulin levels to the incidence of myocardial infarction and coronary heart disease mortality in a middle-aged population. Diabetologia 19:205-210

22. Tobey TA, Greenfield M, Kraemer F, Reaven GM (1981) Relationship between insulin resistance, insulin secretion, very low density lipoprotein kinetics and plasma triglyceride levels in normotriglyceridemic man. Metabolism 30: 165-171

23. Ferrannini E, Buzzigoli G, Bonnadonna R, Gioricco MA, Oleggini M, Graziadei L, Pedrinelli R, Brandi L, Bevilacqua S (1987) Insulin resistance in essential hypertension. $\mathrm{N}$ Engl J Med 317: 350-357

24. Fossati P, Romon-Rousseaux M (1987) Insulin and HDL-cholesterol metabolism. Diab Métab (Paris) 13:390-394

25. Bogardus C, Lillioja S, Howard B, Reaven GM, Mott D (1984) Relationships between insulin secretion, insulin action and fasting plasma glucose concentration in non-diabetic and non-insulin-dependent diabetic subjects. J Clin Invest 74: 1238-1246

26. Modan M, Halkin H, Almog S, Lusky A, Eshkol A, Shefi M, Shitrit A, Fuchs Z (1985) Hyperinsulinemia, a link between hypertension, obesity, and glucose intolerance. J Clin Invest 75 : 809-817

27. Zavaroni I, Bonora E, Pagliara M, Dall' Aglio E, Luchetti L, Buonanno G, Bonati PA, Bergorzani M, Gnudi L, Passeri M, Reaven GM (1989) Risk factors for coronary artery disease in healthy persons with hyperinsulinemia and normal glucose tolerance, N Engl J Med 320:702-706

28. Pyörälä K, Uusitupa M, Laakso M, Siitonen O, Niskanen L, Rönnemaa $T$ (1987) Macrovascular complications in relation to hyperinsulinemia in non-insulin-dependent diabetes mellitus. Diab Métab (Paris) 13: 345-349
29. Reaven GM (1988) Role of insulin resistance in human disease. Diabetes 37: 1595-1607

30. Foster DW (1989) Insulin resistance, a secret killer? N Engl J Med 320: 733-734

31. Castelli WP, Garrison RJ, Wilson PWF, Abbott RD, Kalousdian S, Kannel WB (1986) Incidence of coronary heart disease and lipoprotein cholesterol levels. The Framingham Study. JAMA 256:2835-2838

32. Betteridge DJ (1989) High density lipoprotein cholesterol and coronary heart disease. Br Med J 298: 975-976

33. Castelli WP (1986) The triglyceride issue: a view from Framingham. Am Heart J 112: 432-437

34. Austin MA (1989) Plasma triglyceride as a risk factor for coronary heart disease: the epidemiologic evidence and beyond. Am J Epidemiol 129: 249-259

35. Sicree RA, Zimmet PZ, King HOM, Coventry JS (1987) Plasma insulin response among Nauruans: prediction of deterioration in glucose tolerance over 6 years. Diabetes 36: 179-186

36. Saad MF, Knowler WC, Pettitt DJ, Nelson RG, Mott DM, Bennett PH (1988) The natural history of impaired glucose tolerance in the Pima Indians. N Engl J Med 319: 1500-1506

37. Charles MA, Fontbonne A, Eschwège $E$ (1988) Risk factors of Type 2 (non-insulin-dependent) diabetes in a Caucasian population. Diabetologia 31: 479 (Abstract)

38. Haffner SM, Stern MP, Mitchell BD, Hazuda HP, Patterson JK (1990) Incidence of Type 2 diabetes in Mexican Americans predicted by fasting insulin and glucose levels, obesity, and body fat distribution. Diabetes 39: 283-288

39. Leslie RDG, Volkmann HP, Poncher M, Hanning I, Orskov H, Alberti KGMM (1986) Metabolic abnormalities in children of non-insulin-dependent diabetics. Br Med J 293: 840-842

40. Haffner SM, Stern MP, Hazuda HP, Mitchell BD, Patterson JK (1988) Increased insulin concentrations in non-diabetic offspring of diabetic parents. N Engl J Med 319: 1297-1301

41. Ho LT, Chang ZY, Wang JT, Li SH, Liu YF, Chen YDI, Reaven GM (1990) Insulin insensitivity in offspring of parents with Type 2 diabetes mellitus. Diab Med 7: 31-34

42. Jarrett RJ, Shipley MJ (1988) Type 2 (non-insulin-dependent) diabetes mellitus and cardiovascular disease - putative association via common antecedents; further evidence from the Whitehall Study. Diabetologia 31: 737-740

Received: 12 July 1990

and in revised form: 7 January 1991

Dr. A.Fontbonne

INSERM U21

16 avenue Paul Vaillant Couturier

F-94807 Villejuif Cedex

France 